\title{
ALTERAÇÕES QUÍMICAS DO SOLO E RESPOSTA DA SOJ A AO CALCÁRIO E GESSO APLICADOS NA IMPLANTAÇÃO DO SISTEMA PLANTIO DIRETO(1)
}

\author{
E. F. CAIRE $S^{(2)}$, J . BLUM(3), G. BARTH ${ }^{(3)}$ \\ F. J . GARBUIO ${ }^{(3)} \&$ M. T. KUSMAN ${ }^{(4)}$
}

\begin{abstract}
RESUMO
Na região sul do Brasil, tem aumentado o interesse pela busca de alternativas para a instalação de culturas, no sistema plantio direto, em áreas novas, sem proporcionar revolvimento do solo. Com o objetivo de avaliar as alterações químicas do solo e a resposta da soja ao calcário e gesso aplicados no sistema plantio direto, foi realizado um experimento em um Latossolo Vermel ho distrófico textura argilosa, em Ponta Grossa (PR), no período de 1998 a 2001 . Os tratamentos, dispostos em blocos completos ao acaso em parcelas subdivididas, com três repetições, constaram da aplicação de calcário dolomítico (sem calcário e 4,5 t ha-1 de calcário na superfície, em dose total e 1/3 da dose por ano durante três anos, e incorporado), nas parcelas, e doses de gesso $\left(0,3,6\right.$ e $\left.9 \mathrm{t} \mathrm{ha}^{-1}\right)$, nas subparcelas. A correção da acidez pela calagem na superfície ou incorporada foi mais acentuada na camada superficial do solo $(0-5 \mathrm{~cm})$ e houve maior reação nas profundidades de 5-10 e 10-20 cm, quando o calcário foi incorporado. Os efeitos benéficos da calagem na correção da acidez do subsolo foram pouco pronunciados e mais evidentes com a incorporação do calcário no solo. 0 gesso melhorou o subsolo, aumentando o pH $\left(\mathrm{CaCl}_{2} \mathbf{0 , 0 1} \mathrm{mol} \mathrm{L}^{-1}\right)$ e os teores de $\mathrm{Ca}$ e $\mathrm{S}-\mathrm{SO}_{4}{ }^{2-}$, aumentou a concentração de $\mathrm{P}$ na camada superficial do solo $(0-5 \mathrm{~cm})$ e no tecido foliar da soja e reduziu o Mg no solo e nas folhas. Não houve resposta da soja, em três cultivos, ao calcário e gesso aplicados. Concluiu-se que a aplicação de gesso agrícola, associada ou não à calagem na superfície ou com incorporação, não foi uma estratégia interessante para o estabelecimento da soja no sistema plantio di reto, por não ocasionar melhoria na produção de grãos.
\end{abstract}

Termos de indexação: Glycinemax (L.) Merrill, acidez, subsolo, nutrição mineral.

(1) Trabalho realizado com auxílio financeiro do CNPq. Recebido para publicação em junho de 2002 e aprovado em dezembro de 2002.

(2) Professor do Departamento de Ciência do Solo e Engenharia Agrícola, Universidade Estadual de Ponta Grossa - UE PG. Av. Gal . Carlos Cavalcanti 4748, CEP 84030-900 Ponta Grossa (PR). Bolsista do CNPq. E-mail: efcaires@uepg.br

(3) Aluno do curso de Agronomia, PIC/UEPG.

(4) Aluno do curso de Agronomia, UEPG. Bolsista do PIBIC/CNPq. 


\title{
SUMMARY: CHANGES IN CHEMICAL SOIL CHARACTERISTICS AND SOYBEAN RESPONSE TO LIME AND GYPSUM APPLICATIONS IN A NO-TILLAGE SYSTEM
}

\begin{abstract}
There has been an increasing interest to search alternatives for the establishment of crops under no-tillagesystems in thesouthern region of Brazil , opening up new areas without soil disturbance. A field trial was carried out on a dystrophic Clay Rhodic Hapludox in Ponta Grossa, Paraná State, Brazi I, from 1998 to 2001, with theaim to eval uatechanges in chemical soil characteristics, as well as thesoybean responsetolimeand gypsum applications in a no-tillage system. A completely randomized block design with three replications in a split-pl ot experiment was used. Themain plots received dol omitic limestonetreatments (no lime, total rate of $4.5 \mathrm{t} \mathrm{ha}^{-1}$ of lime, $1 / 3$ of this dosage during three years, as surface application and incorporated into the soil) and the subplots, thegypsum rates $(0,3,6$, and $\left.9 \mathrm{t} \mathrm{ha}^{-1}\right)$. Liming, whether surface applied or incorporated into the soil, provided a more accentuated soil aci dity correction in thesuperficial layer $(0-5 \mathrm{~cm})$, but therewas a stronger reaction in the 5-10 and $10-20 \mathrm{~cm}$ layers when lime was incorporated into the soil. The beneficial effects of lime for subsoil acidity correction were not very pronounced and more evident where lime was incorporated. Gypsum improved the subsoil, increasing the $\mathrm{pH}$ $\left(\mathrm{CaCl}_{2} 0.01 \mathrm{~mol} \mathrm{~L}^{-1}\right), \mathrm{Ca}$, and $\mathrm{S}-\mathrm{SO}_{4}{ }^{2-}$ concentrations, $\mathrm{P}$ concentrations in the superficial soil layer $(0-5 \mathrm{~cm})$ and in soybean leaves, and decreased $\mathrm{Mg}$ concentrations in the soil and soybean leaves. Results showed no soybean response, in three years, to lime and gypsum treatments. It was concluded that gypsum, whether applied as superficial or incorporated liming, did not present an interesting strategy for theinstallation of soybean crop in a notillage system, since no improvement in grain yields could be observed.
\end{abstract}

Index terms: Glycine max (L.) Merrill, acidity, subsoil, mineral nutrition.

\section{INTRODUÇÃO}

A acidez do solo limita a produção agrícola em consideráveis áreas no mundo, em decorrência da toxidez causada por Al e Mn e baixa saturação por bases (Coleman \& Thomas, 1967). No Brasil, aumentos na produção de soja com a calagem têm sido demonstrados por seu efeito no aumento do $\mathrm{pH}$ (Raij et al., 1977), na redução de Al e Mn tóxicos (Mascarenhas et al., 1982), no aumento da absorção deN, P, K eS (Quaggio et al., 1993) e nofornecimento de Ca e Mg (Mascarenhas et al., 1976). A reação do cal cário, entretanto, é geralmente limitada ao local de sua aplicação no solo. A calagem não tem um efeito rápido na redução da acidez do subsolo, que depende da lixiviação de sais através do perfil do solo.

O gesso agrícola, um subproduto da indústria de áci do fosfórico que contém princi palmente sul fato de cálcio e pequenas concentrações de $P$ e $F$, é largamente disponível em muitas partes do mundo. Somente no Brasil, cerca de 3,3 mil hões detoneladas são produzidos anualmente (Freitas, 1992). A eficiência do gesso na mel horia dos efeitos da acidez no subsol o tem sido demonstrada em vários trabal hos (Oates \& Caldwell, 1985; Marsh \& Grove, 1992; Carvalho \& Raij, 1997). A aplicação de gesso na superfície seguida por lixiviação para subsolos ácidos resulta em melhor crescimento radicular e maior absorção de água e nutrientes pelas raízes das plantas (Sumner et al., 1986; Carvalho \& Raij, 1997), em decorrência do aumento da concentração de Ca, da formação de espécies menos tóxicas de Al $\left(\mathrm{AlSO}_{4}{ }^{+}\right.$) e da preci pitação de $\mathrm{Al}^{3+}$ (Shainberg et al., 1989). O gesso agrícola mostra-se mais efetivo na redução da toxidez de Al do que o sulfato de cálcio puro por causa da presença de $\mathrm{F}$-, um ânion que forma complexos mais estáveis com Al do que o $\mathrm{SO}_{4}{ }^{2-}$ (Cameron et al., 1986).

Em casos de sol os com concentração muito baixa de $\mathrm{Al}$, mas com baixa concentração de $\mathrm{Ca}$, o suprimento de cálcio éo principal fator responsável pelo melhor crescimento do sistema radicular (Ritchey et al., 1982). Ainda há dúvidas, no entanto, sobre as condições em que se podem esperar efeitos favoráveis do gesso nas produções das culturas e sobre o método de recomendação do produto.

Na regiãosul do Brasil, temaumentadoointeresse pela busca de alternativas para o estabel ecimento de culturas, no sistema plantio direto, em áreas novas, sem proporcionar revolvimento do solo. As vantagens desse procedimento estão relacionadas com a manutenção de atributos químicos e estruturais do solo, com o maior controle da erosão e com a economia com as operações de incorporação de cal cário e preparo do solo. Considerando que a 
calagem na superfície, em solos nunca utilizados para a produção de grãos, pode ter ação limitada nas camadas superficiais, principalmente nos primeiros anos de cultivo, é possível que a aplicação de gesso agrícola possa compensar esse efeito mediante melhoria do ambiente radicular no subsolo, sem necessidade de incor poração do cal cário no sistema plantio direto.

O presente trabal ho foi realizado com o objetivo de avaliar as alterações químicas do solo, a nutrição mineral e a produção de soja, considerando a aplicação da calagem na superfície, com ou sem parcelamento, e com incorporação, e de doses de gesso no sistema plantio direto.

\section{MATERIAL E MÉTODOS}

O experimento foi realizado no município de Ponta Grossa (PR), Fazenda Regina, em um Latossolo Vermelho distrófico textura argilosa, até então utilizado para pastagem. Análises químicas (Pavan et al., 1992) e granulométricas (E MBRAPA, 1997) do solo, da camada de 0-20 cm, efetuadas antes da instalação do experimento, revelaram os seguintes resultados: $\mathrm{pH}$ em $\mathrm{CaCl}_{2}$ 0,01 mol L-1 4,6; $78 \mathrm{mmol}_{\mathrm{C}} \mathrm{dm}^{-3}$ de $\mathrm{H}+\mathrm{Al} ; 3 \mathrm{mmol}_{\mathrm{C}} \mathrm{dm}^{-3}$ de $\mathrm{Al}^{3+}$; $25 \mathrm{mmol}_{\mathrm{c}} \mathrm{dm}^{-3}$ de $\mathrm{Ca}^{2+} ; 20 \mathrm{mmol}_{\mathrm{c}} \mathrm{dm}^{-3}$ de $\mathrm{Mg}^{2+}$; $3,6 \mathrm{mmol}_{\mathrm{c}} \mathrm{dm}^{-3}$ de $\mathrm{K}^{+} ; 0,3 \mathrm{mg} \mathrm{dm}^{-3}$ de $\mathrm{P}$ (Mehlich1); $31 \mathrm{~g} \mathrm{dm}^{-3}$ de C-orgânico e 38 \% de saturação por bases e teores de argila, silte e areia, respectivamente, de 580, 130 e $290 \mathrm{~g} \mathrm{~kg}^{-1}$. O solo também apresentava $6 \mathrm{mmol}_{\mathrm{c}} \mathrm{dm}^{-3}$ de $\mathrm{Ca}^{2+}$, $8 \mathrm{mmol}_{\mathrm{c}} \mathrm{dm}^{-3} \mathrm{deAl}^{3+} \mathrm{e}^{2} 620 \mathrm{~g} \mathrm{~kg}^{-1}$ deargila no subsolo (40-60 cm).

O delineamento experimental empregado foi o de blocos completos ao acaso em parcelas subdivididas, com três repetições. Nas parcelas, foram aplicados quatro tratamentos de calcário dolomítico, com $89 \%$ de poder relativo de neutralização total (PRNT): testemunha (sem calcário); calcário parcelado na superfície (três aplicações anuais de 1,5 t ha-1); cal cário na superfície $\left(4,5 \mathrm{t} \mathrm{ha}^{-1}\right)$ e cal cário incorporado $\left(4,5 \mathrm{t} \mathrm{ha}^{-1}\right)$. A dose de calcário utilizada foi definida de acordo com o método da elevação da saturação por bases para $70 \%$, em amostra de sol o col etada na profundidade de $0-20 \mathrm{~cm}$. Nas subparcelas, foram aplicadas, em superfície, quatro doses de gesso agrícola: 0, 3, 6 e 9 t ha-1.

As aplicações de calcário dolomítico e de gesso foram realizadas, respectivamente, em julho e em outubro de 1998. O calcário, no tratamento com incorporação, foi aplicado em duas etapas. A primeira etapa constou de aplicação manual de metade da dose antes da aração com arado de discos, a $20 \mathrm{~cm}$ de profundidade. Na segunda etapa, aplicou-seo restante do cal cário, manualmente, após a aração e pouco antes da gradagem, com grade niveladora. A mobilização do solo, no tratamento com incorporação de calcário, ocorreu somente na instalação do experimento. No tratamento com parcelamento anual de calcário na superfície, a segunda aplicação foi efetuada em maio de 1999 ea terceira em maio de 2000. As ár eas de cada parcela e subparcela foram, respectivamente, de 224 e $56 \mathrm{~m}^{2}$.

Realizaram-setrês cultivos de soja, na densidade de 20 sementes por metro linear e espaçamento de $0,45 \mathrm{~m}$ entre as linhas. Foram utilizados os cultivares FT 5 (1998/99), FT Abyara (1999/2000) e EMBRAPA 133 (2000/2001). Como adubação básica, empregaram-se $300 \mathrm{~kg} \mathrm{ha}^{-1}$ da fórmula 0-25-25 (N$\mathrm{P}_{2} \mathrm{O}_{5}-\mathrm{K}_{2} \mathrm{O}$ ) com $5 \%$ de $\mathrm{S}$ no primeiro cultivo e $250 \mathrm{~kg} \mathrm{ha}^{-1}$ da fórmula 0-20-20 (N- $\left.\mathrm{P}_{2} \mathrm{O}_{5}-\mathrm{K}_{2} \mathrm{O}\right)$ com $5 \%$ de $S$ no segundo e terceiro cultivo. Realizou-se, também, a inoculação das sementes com estirpes selecionadas de Bradyrhizobium japonicum. No inverno de 1999, a área experimental foi cultivada com cevada e, no inverno de 2000 , com trigo. A temperatura média durante o ciclo da cultura da soja foi de $22,0,21,1$ e $22,5{ }^{\circ} \mathrm{C}$, respectivamente, no primeiro, segundo eterceiro cultivo. A precipitação pluvial ocorrida durante os meses de julho a junho, nos anos de 1998/1999, 1999/2000 e 2000/2001 foi, respectivamente, de 1.959, 1.148 e $2.104 \mathrm{~mm}$.

No início do florescimento da cultura, foi feita amostragem de fol has, col etando-se a terceira fol ha a partir do ápice das plantas, em número de 30 por subparcela, para análise química dos teores de $\mathrm{N}$, P, K, Ca, Mg, S, Zn e Mn (Malavolta et al., 1997).

Após a maturação, a soja foi colhida e trilhada, sendo então determi nada a produção de grãos a $13 \%$ de umidade. Foram col hidas as seis linhas centrais por quatro metros de comprimento em cada subparcela, tendo sido desprezados dois metros de cada extremidade.

Amostras de solo foram coletadas anualmente, após a colheita da soja, ao acaso, nas linhas e entre as linhas da cultura. As amostragens foram realizadas 11, 23 e 35 meses após a calagem, correspondendo a aproximadamente 8, 20 e 32 meses após a aplicação de gesso. Retiraram-se, por meio de trado, 12 subamostras por subparcela para compor uma amostra composta das camadas de 0-5, 5-10 e 10-20 cm, e cinco subamostras para as camadas de $20-40$ e $40-60 \mathrm{~cm}$ de profundidade. Foram determinados o pH em $\mathrm{CaCl}_{2} 0,01 \mathrm{~mol} \mathrm{~L}^{-1} \mathrm{e}$ os teores de $\mathrm{Al}^{3+}, \mathrm{Ca}^{2+}, \mathrm{Mg}^{2+}$ eP (Mehlich-1), segundo os métodos descritos por Pavan et al. (1992). Os teores de $\mathrm{P}$ foram determinados somente em amostras de solo coletadas até à profundidade de $20 \mathrm{~cm}$. As alterações nos teores de $\mathrm{Ca}^{2+} \mathrm{eMg}^{2+}$ foram aval iadas apenas para as doses 0 e $9 \mathrm{t} \mathrm{ha}^{-1}$ de gesso, após 8 e 32 meses, considerando os tratamentos de calagem. Análises de $\mathrm{S}-\mathrm{SO}_{4}{ }^{2-}$, nas diferentes profundidades do solo, também foram feitas, 
mediante extração pelo acetato de amônio 0,5 mol L-1 em ácido acético 0,25 mol L-1 eposterior determinação pelo método turbidimétrico, descrito por Vitti \& Suzuki (1978).

Os resultados foram submetidos às análises de variância e de regressão. Na ausência de interação significativa entre os tratamentos de cal cário e as doses de gesso sobre as variáveis estudadas, os efeitos da calagem foram comparados pelo teste de Tukey a $5 \%$ e do gesso por meio de análises de regressão, pelas médias das observações. Adotouse como critério para escol ha do modelo a magnitude dos coeficientes de determinaçãosignificativos a $5 \%$.

\section{RESULTADOS E DISCUSSÃO}

Os aumentos no pH com a calagem foram mai ores na camada superficial do sol o $(0-5 \mathrm{~cm})$, independentemente do modo deaplicação do cal cário, e decresceram com o aumento da profundidade do solo, principalmente quando o calcário foi aplicado na superfície ( $F$ igura 1 ). Os efeitos da calagem na superfície sobre o pH do solo foram significativos somente na profundidade de 0-5 cm, após 11 meses (1999), enas profundidades de 5-10 e 10-20 cm, após 23 meses (2000), e de $20-40$ cm, após 35 meses (2001) da aplicação do calcário. A aplicação anual de 1/3 da dose de calcário na superfície por três anos proporcionou somente uma reação mais lenta do corretivo na camada superficial do solo $(0-5 \mathrm{~cm})$ em relação à aplicação em dose única. A maior reação do cal cário aplicado superficialmente, com ou sem o parcelamento da dose, ocorreu 35 meses após a calagem (2001).

Verificou-se, em outros trabalhos, que o tempo ocorrido para a máxima reação do cal cário aplicado na superfície foi de 32 meses em um Latossolo Vermel ho argiloso (Oliveira \& Pavan, 1996) e de 28 a 30 meses em um Latossolo Vermelho textura média (Caires et al., 2000). O cal cário incorporado aumentou o pH do solo de forma semel hante à calagem superficial, em dose única, na camada de 0-5 cm; apresentou, porém, reaçãosignificativamente maior nas profundidades de $5-10$ e $10-20 \mathrm{~cm}$. Mesmo com a incorporação, a maior reação do cal cário nas camadas superficiais do solo ocorreu entre 23 e 35 meses após a aplicação. Esse tempo de reação foi semel hanteao obtido por Camargo et al. (1982) e Oliveira et al. (1997) com o cal cário incorporado na camada arável em sistema convencional de preparo do solo. É interessante notar que o cal cário, quando incorporado, proporcionou aumento significativo do pH no subsolo (20-40 e 40-60 cm) após 11 meses, que permaneceu consistente até 35 meses após a sua aplicação.

Os resultados quanto à eficiência da calagem na neutralização da acidez de subsolos são aparentemente discordantes na literatura. Alguns trabal hos revelam que o cal cário não se movimenta para camadas mais profundas do solo (Ritchey et al., 1980; Pavan et al., 1984), enquanto outros mostraram consideráveis aumentos no pH abaixo da região de aplicação do calcário, em áreas de cultivos anuais, preparadas convencionalmente (Quaggio et al., 1993; Oliveira et al., 1997) ou manejadas no sistema plantio direto (Oliveira \& Pavan, 1996; Caires et al., 2000), e decultivos perenes estabel ecidos (Chaves et al., 1984; Pavan, 1994).

A ação do cal cário na neutralização da acidez de subsol os é dificultada pelo aumento da retenção de cátions em decorrência da geração de cargas el étricas variáveis negativas com a el evação do $\mathrm{pH}$ do solo. Além disso, os ânions resultantes de sua dissol ução, responsáveis pela correção da acidez, são também consumidos nas reações com outros cátions ácidos $\left(\mathrm{Al}^{3+}, \mathrm{Mn}^{2+}\right.$ e $\left.\mathrm{Fe}^{2+}\right)$ na camada de deposição do calcário. No entanto, o aumento do $\mathrm{pH}$ na superfície do solo pode acelerar a velocidade com que o $\mathrm{HCO}_{3}{ }^{-}$, acompanhado por Ca e Mg, movimenta-se para o subsolo para reagir com a acidez.

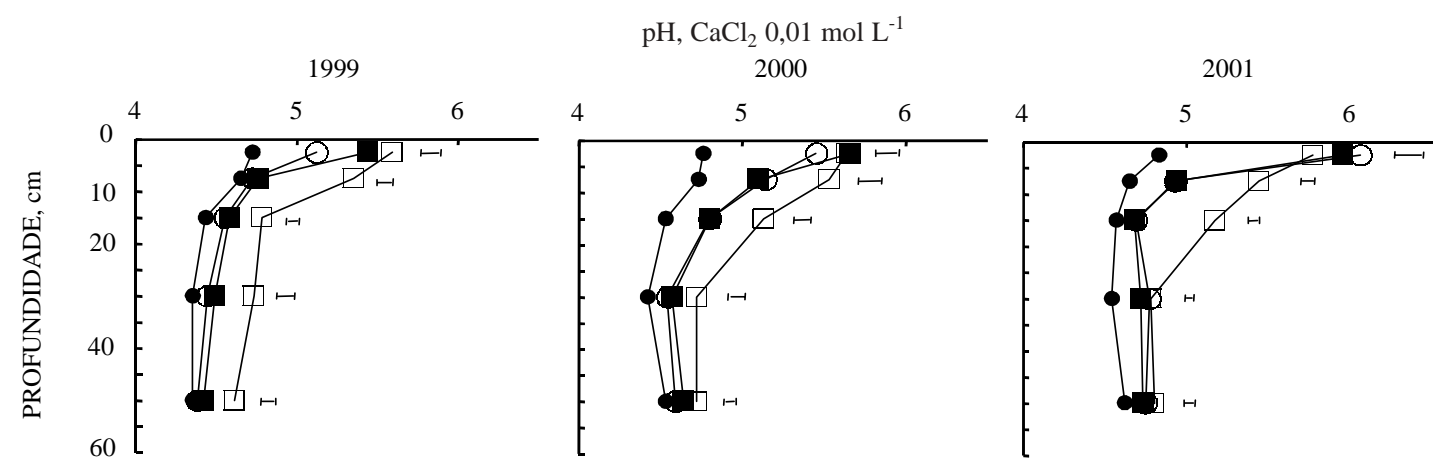

Figura 1. Alterações no pH em $\mathrm{CaCl}_{2} 0,01 \mathrm{~mol} \mathrm{~L}^{-1}$, em diferentes profundidades do solo, considerando os tratamentos de calagem: sem calcário $(\bullet), 1 / 3$ da dose de calcário anualmente na superfície durante três anos $(O)$, calcário em dose total na superfície ( $\square$ ) e calcário incorporado ( $\square$ ), em três épocas de amostragem: 11 (1999), 23 (2000) e 35 (2001) meses após a aplicação. Barras horizontais indicam o DMS pelo teste de Tukey $(P=0,05)$. 
Os efeitos da calagem em profundidade somente devem ocorrer quando o pH (em água), na zona de dissolução do calcário, atingir valores da ordem de 5,2 a 5,6 (Helyar, 1991; Rheinheimer et al., 2000). A formação ea mi gração de $\mathrm{Ca}\left(\mathrm{HCO}_{3}\right)_{2} \mathrm{e} \mathrm{Mg}\left(\mathrm{HCO}_{3}\right)_{2}$ para as camadas mais profundas do sol o constituem a hipótese que melhor justifica a diminuição da acidez no subsol o pela calagem, na superfície ou com incorporação, no sistema plantio direto (Costa, 2000).

Vale destacar que o deslocamento mecânico de partículas de calcário através de canais formados por raízes mortas, mantidos intactos em razão da ausência de preparo do solo (Pavan, 1994), e a formação de complexos orgânicos solúveis por meio do manejo de resíduos vegetais (Miyazawa et al., 1996; Oliveira \& Pavan, 1996) também podem influenciar a eficiência da calagem na correção da acidez do subsolo. De qualquer forma, os resultados mostram claramente que os efeitos benéficos da calagem na correção da acidez do subsolo foram pouco pronunciados e mais evidentes quando da incorporação do cal cário no solo.

A aplicação de doses de gesso não exerceu influência sobre a acidez nas camadas superficiais do solo, mas causou el evação do $\mathrm{pH}\left(\mathrm{CaCl}_{2}\right.$ $0,01 \mathrm{~mol} \mathrm{~L}^{-1}$ ) no subsolo (Quadro 1). Tal efeito foi observado nas camadas de solo de $20-40 \mathrm{~cm}$ (8 meses) e 40-60 cm (8, 20 e 32 meses). O aumento do $\mathrm{pH}$ no subsolo, por meio da aplicação de gesso, também foi verificado em outros trabalhos (Carvalho

Quadro 1. Equações de regressão ajustadas para pH em $\mathrm{CaCl}_{2} 0,01 \mathrm{~mol} \mathrm{~L}^{-1}(\hat{Y})$, em diferentes profundidades do solo, considerando a aplicação de doses de gesso na superfície $\left(x, t h^{-1}\right)$, após 8 (1999), 20 (2000) e 32 (2001) meses

\begin{tabular}{|c|c|c|c|}
\hline Profundidade & Ano & E quação de regressão & $\mathbf{R}^{2}$ \\
\hline \multicolumn{4}{|l|}{$\mathrm{cm}$} \\
\hline \multirow[t]{3}{*}{$0-5$} & 1999 & $\hat{\mathrm{Y}}=\overline{\mathrm{Y}}=5,2$ & - \\
\hline & 2000 & $\hat{\mathrm{Y}}=\overline{\mathrm{Y}}=5,4$ & - \\
\hline & 2001 & $\hat{\mathrm{Y}}=\overline{\mathrm{Y}}=5,7$ & - \\
\hline \multirow[t]{3}{*}{$5-10$} & 1999 & $\hat{\mathrm{Y}}=\overline{\mathrm{Y}}=4,9$ & - \\
\hline & 2000 & $\hat{\mathrm{Y}}=\overline{\mathrm{Y}}=5,1$ & - \\
\hline & 2001 & $\hat{\mathrm{Y}}=\overline{\mathrm{Y}}=5,0$ & - \\
\hline \multirow[t]{3}{*}{$10-20$} & 1999 & $\hat{\mathrm{Y}}=\overline{\mathrm{Y}}=4,6$ & - \\
\hline & 2000 & $\hat{\mathrm{Y}}=\overline{\mathrm{Y}}=4,8$ & - \\
\hline & 2001 & $\hat{\mathrm{Y}}=\overline{\mathrm{Y}}=4,8$ & - \\
\hline \multirow[t]{3}{*}{$20-40$} & 1999 & $\hat{Y}=4,397+0,024^{* *} x$ & 0,85 \\
\hline & 2000 & $\hat{\mathrm{Y}}=\overline{\mathrm{Y}}=4,6$ & - \\
\hline & 2001 & $\hat{\mathrm{Y}}=\overline{\mathrm{Y}}=4,7$ & - \\
\hline \multirow[t]{3}{*}{$40-60$} & 1999 & $\hat{\mathrm{Y}}=4,338+0,023^{* *} \mathrm{x}$ & 0,90 \\
\hline & 2000 & $\hat{\mathrm{Y}}=4,537+0,019^{* *} \mathrm{X}$ & 0,96 \\
\hline & 2001 & $\hat{\mathrm{Y}}=4,675+0,014^{* *} \mathrm{x}$ & 0,65 \\
\hline
\end{tabular}

\& Raij, 1997; Caires et al., 1999) etem sido atribuído a uma reação de troca de ligantes na superfície das partículas de solo, envolvendo óxidos hidratados de ferro e alumínio, com o $\mathrm{SO}_{4}{ }^{2-}$ deslocando $\mathrm{OH}^{-}$e, assim, promovendo neutralização parcial da acidez (Reeve \& Sumner, 1972).

A aplicação de cal cário dolomítico na superfície aumentou os teores de Ca e Mg trocáveis, notadamente na camada superficial do solo $(0-5 \mathrm{~cm})$, de forma mais lenta e contínua do que quando o cal cário foi incorporado no solo (Figura 2). Tal efeito foi ainda mais evidente na camada superficial com o parcelamento da dose de calcário na superfície (1/3 da dose aplicada anual mente por três anos). O calcário incorporado proporcionou aumento nos teores de $\mathrm{Ca}$ e $\mathrm{Mg}$ trocáveis, principalmente, nas camadas superficiais $(0-5$ e 5-10 cm) e, em menor magnitude, nas camadas mais profundas do solo, conforme o tempo de reação do corretivo. O gradiente de concentração de Ca e Mg trocáveis, a partir da superfície do solo, foi mais acentuado com a calagem superficial do que com o calcário incorporado.

A aplicação de gesso aumentou os teores de $\mathrm{Ca}$ trocável do sol o nas cinco profundidades estudadas, independentemente dos tratamentos de calagem (F igura 2). O aumento do Ca trocável no perfil do solo com o uso de gesso foi mais pronunciado aos oito meses (1999) de sua aplicação na superfície, sendo nítida a lixiviação do nutriente com a maior dose de gesso aplicada ( 9 t ha- $^{-1}$ ), após 32 meses (2001). O gesso causou intensa movimentação de Mg trocável no solo, proporcional à elevação dos teores do nutriente pela aplicação de calcário dolomítico na superfície, com ou sem parcelamento, e com incor poração.

Após oito meses (1999), houve redução de Mg trocável nas camadas superficiais do sol o e aumento nas concentrações do nutriente em camadas do subsolo, com a aplicação de gesso. Após 32 meses (2001), o gesso continuou promovendo lixiviação de $\mathrm{Mg}^{2+}$ em maiores profundidades. A lixiviação de $\mathrm{Mg}$ trocável tem sido uma resposta freqüente nos estudos com aplicação de gesso em sol os (Oliveira \& Pavan, 1996; Caires et al., 1999). Assim, quando o gesso é aplicado em doses el evadas no solo, devem ser desenvolvidas estratégias para minimizar as perdas de Mg trocável. Nesse caso, a aplicação de cal cário dol omítico, em dose parcelada na superfície, poderia trazer maiores benefícios, por garantir mai ores teores de Mg trocável na camada superficial do solo.

Os teores de $\mathrm{S}-\mathrm{SO}_{4}{ }^{2-}$ no solo não foram alterados, de forma significativa, pelos tratamentos de calagem, encontrando-se, nas cinco profundidades estudadas, concentrações médias de 14,3, 16,6 e 9,9 $(0-5 \mathrm{~cm}), 9,1,13,0$ e $12,1(5-10 \mathrm{~cm}), 7,6,13,0$ e 15,7 $(10-20 \mathrm{~cm}), 7,2,14,0$ e $21,8(20-40 \mathrm{~cm})$ e $6,0,9,0$ e $15,0(40-60 \mathrm{~cm}) \mathrm{mg} \mathrm{dm}^{-3}$, respectivamente, em 1999, 
Ca, TROCÁVEL, $\mathrm{mmol}_{\mathrm{c}} \mathrm{dm}^{-3}$
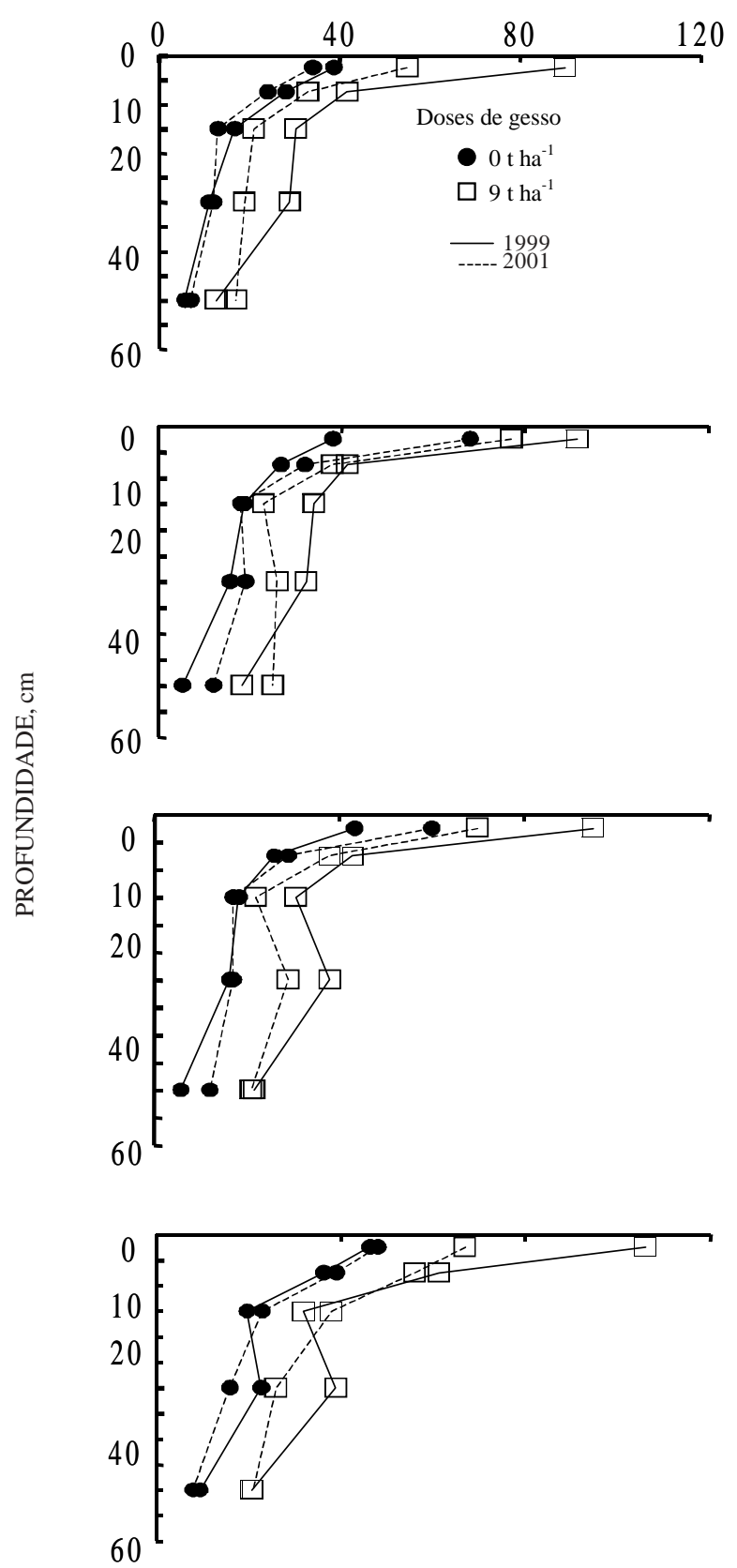

(a)

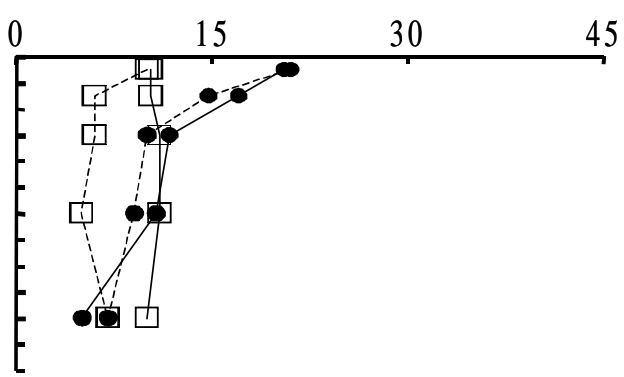

(b)

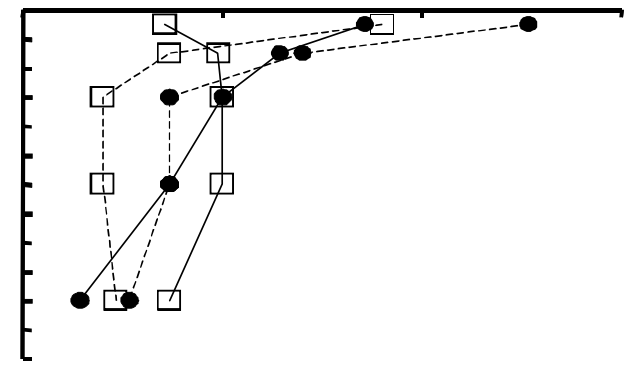

(c)

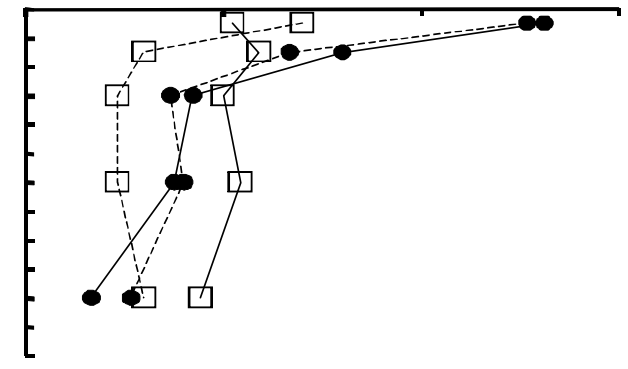

(d)

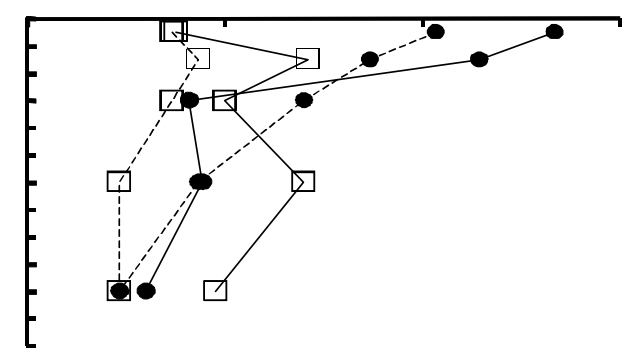

Figura 2. Efeito de doses de gesso na superfície, após 8 (1999) e 32 (2001) meses, sobre os teores de Ca e Mg trocáveis, em diferentes profundidades do solo, considerando os tratamentos de calagem: sem calcário (a), 1/3 da dose de calcário anualmente na superfície durante três anos (b), calcário em dose total na superfície (c) e calcário incorporado (d).

2000 e 2001. O decréscimo nos teores de sulfato com a profundidade, observado no primeiro ano, decorre deausência de adubações anteriores com fertilizantes que continham enxofre. Os teores desulfato no solo aumentaram com o tempo, dependendo de cultivos com adubações que continham enxofre acumulado no subsolo.
A aplicação de doses de gesso aumentou os teores deS-SO ${ }_{4}^{2-}$ nosolo, nas cinco profundidades estudadas (Figura 3). Nota-se que houve movimentação de sulfato no solo proporcional às doses de gesso, dependendo do tempo da aplicação. O maior acúmulo de $\mathrm{S}-\mathrm{SO}_{4}{ }^{2-}$ no solo ocorreu na camada superficial $(0-5 \mathrm{~cm})$, após oito meses, e no subsolo 

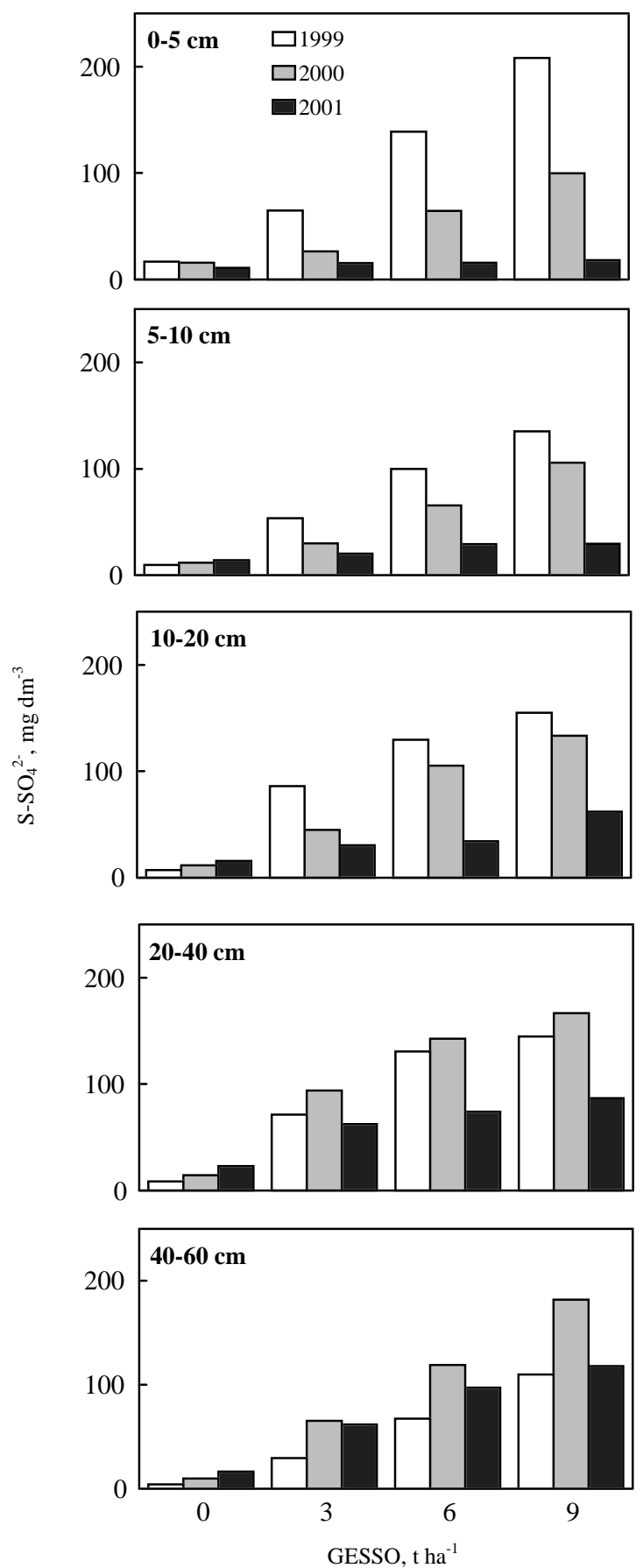

Figura 3. Teores de enxofre no solo, em diferentes profundidades, considerando a aplicação de doses de gesso na superfície, após 8 (1999), 20 (2000) e 32 (2001) meses.

(40-60 cm), após 20 e 32 meses. O S-SO ${ }_{4}^{2-}$ do gesso foi distribuído regularmente pelo perfil do solo, ao invés de ficar acumulado em alguma camada, concordando com os resultados obtidos por Sousa \& Ritchey (1986). Intensa movimentação do S-SO ${ }_{4}^{2-}$ do gesso, das camadas superficiais para o subsolo, foi observada 32 meses após a sua aplicação. A velocidadecom que o sulfato se movimenta évariável em diferentes solos (Quaggio et al., 1993; Caires et al., 1998), devendo ser mais lenta em sol os com mai or teor de argila.

Os tratamentos de calagem não causaram alterações significativas nos teores de P (Mehlich-1) no solo, obtendo-se, até à profundidade de $20 \mathrm{~cm}$, concentrações médias de 4,4, 4,3 e 5,1 (0-5 cm), 1,0, 1,7 e 1,6 (5-10 cm) e 0,6, 1,2 e 0,6 (10-20 cm) mg dm-3, respectivamente, em 1999, 2000 e 2001 . N ota-se que houve acentuada diminuição no teor de $\mathrm{P}, \mathrm{a}$ partir da superfície do solo, ocorrência comum em sistema plantio direto(Muzilli, 1983; Sidiras \& Pavan, 1985), considerando a ausência de revolvimento, a liberação de $\mathrm{P}$ durante a decomposição dos resíduos de plantas e as aplicações anuais de fertilizantes fosfatados.

As doses de gesso aumentaram linearmente os teores deP (Mehlich-1) na camada superficial do sol o (0-5 cm), nos três anos de cultivo (Figura 4). Deveseconsiderar que o fósforo contido no gesso agrícola, como impureza, pode ser importante na nutrição vegetal, no caso de aplicações de doses el evadas de gesso (Sumner et al., 1986).

Os teores de nutrientes nas fol has de soja foram pouco influenciados pela calagem, independentemente do modo de aplicação (Quadro 2), e se mantiveram sempre em níveis considerados normais para a cultura (Malavolta et al., 1997). No primeirocultivo, somente o $\mathrm{N}$ foi influenciado pelos tratamentos de calagem. A redução na concentração foliar de N com a incorporação do cal cário pode ter sido ocasionada por efeito de diluição do nutriente nos tecidos da planta. Caires et al. (2001) verificaram quea calagem proporcionou redução no teor de $\mathrm{N}$ nas folhas de soja e aumento no acúmulo de $\mathrm{N}$ pela parte aérea das plantas, em decorrência de maior produção de matéria seca. O calcário incorporado proporcionou maior concentração de Ca eZn nas fol has de soja do que quando aplicado na superfície, em dose única, apenas no segundo cultivo. A calagem reduziu a concentração de $\mathrm{Mn}$ nas fol has de soja, principalmente com a incorporação do calcário no solo, nos dois últimos cultivos.

A maior concentração de Ca nas folhas de soja com a incorporação do cal cário em relação à sua aplicação na superfície também foi observada por Moreira et al. (2001). Redução na concentração foliar e na absorção de Zn pela cultura da soja, com a aplicação de calcário na superfície em sistema plantio direto, tem sido relatada em outros trabal hos (Caires \& Fonseca, 2000; Caires et al., 2001), em razão do aumento do $\mathrm{pH}$ nas camadas superficiais do sol o. Os teores foliares de Zn diminuíram com os cultivos sucessivos, de forma semelhante à observada por Mascarenhas et al. (1988). A calagem reduziu o teor de $\mathrm{Mn}$ nas fol has de soja, em decorrência do aumento do pH (Caires \& Fonseca, 2000) e dos teores de Ca e Mg trocáveis (Ritchey et 

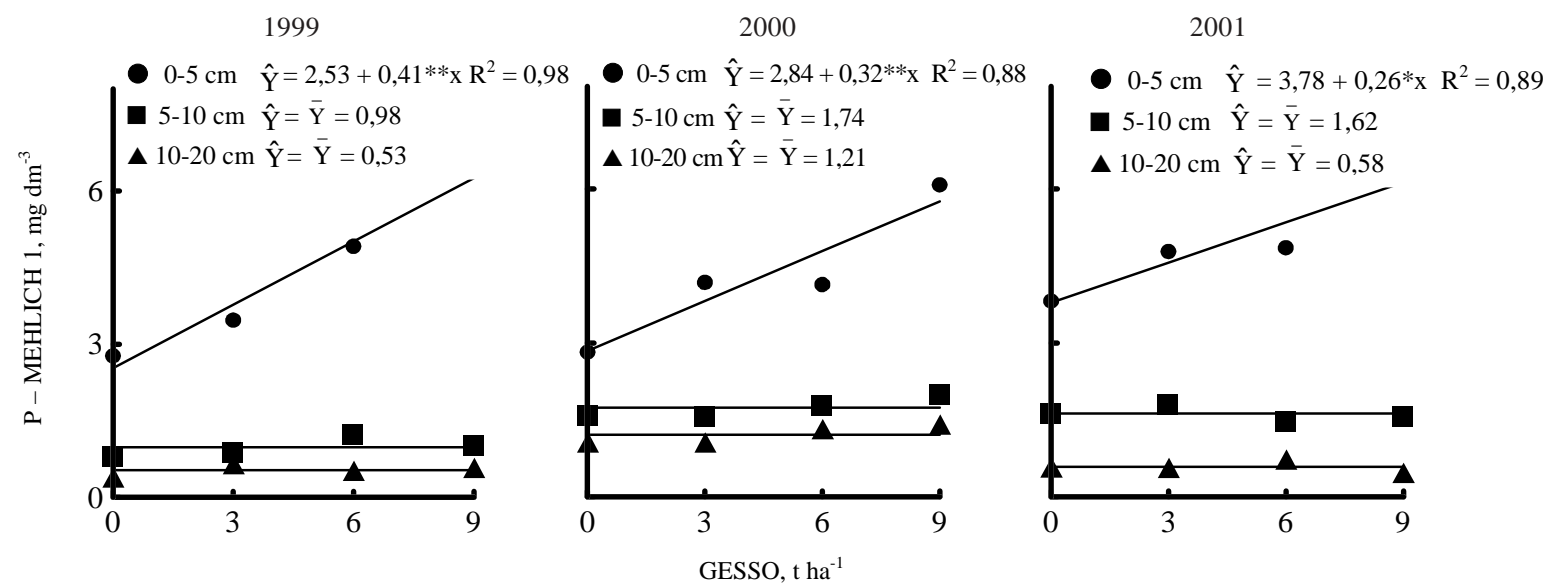

Figura 4. Teores de fósforo no solo, em diferentes profundidades, considerando a aplicação de doses de gesso na superfície, após 8 (1999), 20 (2000) e 32 (2001) meses. *, **: significativo P <0,05 e 0,01, respectivamente.

Quadro 2. Teores de macronutrientes e de zinco e manganês nas fol has de soja, considerando a aplicação de calagem no sistema plantio direto

\begin{tabular}{|c|c|c|c|c|c|c|c|c|c|}
\hline Tratamento & Ano & $\mathbf{N}$ & $\mathbf{P}$ & $\mathbf{K}$ & $\mathrm{Ca}$ & Mg & $\mathbf{S}$ & Zn & Mn \\
\hline & & \multirow{2}{*}{\multicolumn{6}{|c|}{$\mathrm{g} \mathrm{kg}^{-1}$}} & \multicolumn{2}{|c|}{$\ldots \mathrm{mg} \mathrm{kg}^{-1}$} \\
\hline & 1998/1999 & & & & & & & & \\
\hline Sem calcário & & 49,9 & 3,7 & 25,0 & 9,3 & 2,9 & 2,9 & 50,4 & 79,2 \\
\hline Cal cário na superfície(1) & & 49,7 & 3,5 & 24,0 & 10,7 & 3,1 & 2,7 & 50,5 & 84,7 \\
\hline Cal cário na superfície ${ }^{(2)}$ & & 50,8 & 3,7 & 24,2 & 9,6 & 2,9 & 2,9 & 45,5 & 72,3 \\
\hline Cal cário incorporado & & 46,6 & 2,8 & 23,9 & 10,3 & 3,1 & 2,8 & 48,0 & 63,1 \\
\hline DMS $(P=0,05)$ & & 3,1 & 0,9 & 2,9 & 2,1 & 0,3 & 0,4 & 17,6 & 28,0 \\
\hline C.V. (\%) & & 4,5 & 19,3 & 8,5 & 14,8 & 7,7 & 9,6 & 25,6 & 26,4 \\
\hline Sem calcário & 1999/2000 & 524 & 33 & 240 & 121 & 32 & 20 & 374 & 576 \\
\hline Calcário na superfície ${ }^{(1)}$ & & $\begin{array}{l}52,4 \\
51,8\end{array}$ & $\begin{array}{l}3,3 \\
3,4\end{array}$ & $\begin{array}{l}24,0 \\
24,4\end{array}$ & $\begin{array}{l}12,1 \\
12,3\end{array}$ & $\begin{array}{l}3,2 \\
4,1\end{array}$ & $\begin{array}{l}2,0 \\
2,0\end{array}$ & $\begin{array}{l}3 /, 4 \\
43,4\end{array}$ & $\begin{array}{l}51,6 \\
47,8\end{array}$ \\
\hline Cal cário na superfície ${ }^{(2)}$ & & 54,8 & 3,7 & 24,0 & 11,9 & 3,2 & 2,1 & 33,7 & 50,2 \\
\hline Cal cário incorporado & & 50,1 & 3,4 & 24,3 & 12,9 & 3,4 & 2,0 & 45,7 & 44,7 \\
\hline DMS (P =0,05) & & 5,3 & 0,5 & 1,3 & 0,9 & 1,3 & 0,4 & 10,4 & 9,7 \\
\hline C.V. (\%) & & 7,1 & 11,4 & 3,9 & 5,6 & 26,9 & 13,0 & 18,3 & 13,7 \\
\hline & $2000 / 2001$ & & & & & & & & \\
\hline Sem calcário & & 57,1 & 3,6 & 24,0 & 8,5 & 3,4 & 3,3 & 27,0 & 51,8 \\
\hline Cal cário na superfície ${ }^{(1)}$ & & 56,0 & 3,6 & 22,9 & 7,6 & 3,7 & 3,1 & 26,8 & 40,8 \\
\hline Cal cário na superfície(2) & & 55,7 & 3,7 & 22,9 & 7,8 & 3,2 & 3,2 & 23,0 & 39,2 \\
\hline Calcário incorporado & & 57,6 & 3,7 & 23,1 & 8,0 & 3,5 & 3,2 & 25,4 & 36,7 \\
\hline DMS $(P=0,05)$ & & 7,2 & 0,5 & 2,4 & 1,6 & 0,9 & 0,4 & 6,9 & 10,8 \\
\hline C.V. (\%) & & 8,9 & 9,6 & 7,3 & 14,3 & 18,0 & 9,0 & 19,3 & 18,2 \\
\hline
\end{tabular}

al., 1982). Além disso, a correção da acidez do solo provocou maior atividade microbiana que complexa o Mn, tornando-omenos disponível (Tanaka et al., 1993).

Houve aumento linear nas concentrações de $S$ (primeiroano), N (segundoano) eCa (terceiroano) no tecido foliar da soja com as doses de gesso aplicadas (Quadro 3). O teor foliar de Mn foi aumentado linearmente, nos dois primeiros cultivos, e houve aumento de $\mathrm{P}$ e redução de $\mathrm{Mg}$ nas fol has de soja, linear e consistente, nos três anos de cultivo, conforme as doses de gesso. A aplicação de gesso não causou alterações significativas nas concentrações foliares de K eZn. Os teores de nutrientes no tecido foliar mantiveram-se em níveis considerados suficientes para a soja (Malavolta et al., 1997), independentemente das al ter ações ocorridas com as doses de gesso aplicadas. 
Quadro 3. Equações de regressão ajustadas para teores de macronutrientes e de zinco e manganês nas folhas de soja $(\hat{Y})$, considerando a aplicação de doses de gesso na superfície $\left(x, t^{~ h a}{ }^{-1}\right)$ em sistema plantio direto

\begin{tabular}{|c|c|c|c|}
\hline Nutriente & Ano & Equação de regressão & $\mathbf{R}^{2}$ \\
\hline$N\left(g ~ k g^{-1}\right)$ & $\begin{array}{l}1998 / 1999 \\
1999 / 2000 \\
2000 / 2001\end{array}$ & $\begin{array}{l}\hat{Y}=\bar{Y}=49,3 \\
\hat{Y}=48,625+0,815^{* * X} \\
\hat{Y}=\bar{Y}=56,6\end{array}$ & $\begin{array}{c}- \\
0,77 \\
-\end{array}$ \\
\hline$P\left(g ~ k g^{-1}\right)$ & $\begin{array}{l}1998 / 1999 \\
1999 / 2000 \\
2000 / 2001\end{array}$ & $\begin{array}{l}\hat{Y}=3,242+0,040^{* *} \mathrm{X} \\
\hat{Y}=3,192+0,056^{* *} \mathrm{X} \\
\hat{Y}=3,491+0,037^{* *} \mathrm{X}\end{array}$ & $\begin{array}{l}0,95 \\
0,99 \\
0,85\end{array}$ \\
\hline$K\left(g_{k g}^{-1}\right)$ & $\begin{array}{l}1998 / 1999 \\
1999 / 2000 \\
2000 / 2001\end{array}$ & $\begin{array}{l}\hat{Y}=\bar{Y}=24,3 \\
\hat{Y}=\bar{Y}=24,2 \\
\hat{Y}=\bar{Y}=23,2\end{array}$ & $\begin{array}{l}- \\
-\end{array}$ \\
\hline $\mathrm{Ca}\left(\mathrm{g} \mathrm{kg}^{-1}\right)$ & $\begin{array}{l}1998 / 1999 \\
1999 / 2000 \\
2000 / 2001\end{array}$ & $\begin{array}{l}\hat{\mathrm{Y}}=\overline{\mathrm{Y}}=10,0 \\
\hat{\mathrm{Y}}=\overline{\mathrm{Y}}=12,3 \\
\hat{\mathrm{Y}}=7,334+0,139^{* *} \mathrm{X}\end{array}$ & $\begin{array}{c}- \\
- \\
0,99\end{array}$ \\
\hline$M g\left(g ~ k g^{-1}\right)$ & $\begin{array}{l}1998 / 1999 \\
1999 / 2000 \\
2000 / 2001\end{array}$ & $\begin{array}{l}\hat{Y}=3,232-0,052^{* *} x \\
\hat{Y}=3,862-0,089^{*} x \\
\hat{Y}=3,652-0,047^{*} x\end{array}$ & $\begin{array}{l}0,98 \\
0,94 \\
0,89\end{array}$ \\
\hline$S\left(g_{k g}{ }^{-1}\right)$ & $\begin{array}{l}1998 / 1999 \\
1999 / 2000 \\
2000 / 2001\end{array}$ & $\begin{array}{l}\hat{\mathrm{Y}}=2,589+0,055^{* *} \mathrm{X} \\
\hat{\mathrm{Y}}=\overline{\mathrm{Y}}=2,0 \\
\hat{\mathrm{Y}}=\overline{\mathrm{Y}}=3,2\end{array}$ & $\begin{array}{c}0,86 \\
- \\
-\end{array}$ \\
\hline $\mathrm{Zn}\left(\mathrm{mg} \mathrm{kg}^{-1}\right)$ & $\begin{array}{l}1998 / 1999 \\
1999 / 2000 \\
2000 / 2001\end{array}$ & $\begin{array}{l}\hat{\mathrm{Y}}=\overline{\mathrm{Y}}=48,6 \\
\hat{\mathrm{Y}}=\overline{\mathrm{Y}}=40,0 \\
\hat{\mathrm{Y}}=\overline{\mathrm{Y}}=25,5\end{array}$ & $\begin{array}{l}- \\
-\end{array}$ \\
\hline $\mathrm{Mn}\left(\mathrm{mg} \mathrm{kg}^{-1}\right)$ & $\begin{array}{l}1998 / 1999 \\
1999 / 2000 \\
2000 / 2001\end{array}$ & $\begin{array}{l}\hat{Y}=66,958+1,750^{* * X} \\
\hat{Y}=46,408+0,817^{* * X} \\
\hat{Y}=\bar{Y}=42,1\end{array}$ & $\begin{array}{c}0,94 \\
0,84 \\
-\end{array}$ \\
\hline
\end{tabular}

*, **: significativo $\mathrm{P}<0,05$ e 0,01, respectivamente.

A aplicação de gesso agrícola aumentou os teores de Ca trocável e de $\mathrm{S}^{-\mathrm{SO}_{4}}{ }^{2-}$ disponível no solo. No entanto, os efeitos do gesso refl etiram-se no aumento da concentração de $\mathrm{S}$ nas fol has de soja, apenas no primeiro cultivo (Caires et al., 1998), e, em prazo mais longo, no aumento do teor foliar de Ca (Caires et al., 1999). Tais efeitos podem estar relacionados com o movimento mais rápido de $\mathrm{S}-\mathrm{SO}_{4}{ }^{2-}$ do que de $\mathrm{Ca}^{2+}$, em sol os com predominância de carga líquida negativa (Camargo \& Raij, 1989).

Os efeitos do gesso no aumento do teor foliar de $\mathrm{Mn}$ ocorreram nos dois primei ros anos de cultivo da soja (Quadro 3), quando existiam el evados teores de sulfato nas camadas superficiais do solo (Figura 3). Uma possível explicação para esse aumento na concentração de $\mathrm{Mn}$ no teci do fol iar com a aplicação dedoses de gesso seria a formação de par iônico entre esse cátion eo sulfato, diminuindo a atividade desse elemento em solução, favorecendo, assim, o deslocamento do equilíbrio no solo, liberando mais íons Mn para a solução e permitindo maior absorção pelas plantas (Olsen \& Watanabe, 1979). Em solo de cerrado, a deficiência de $\mathrm{Mn}$ em soja foi corrigida com a aplicação do equivalente a $2 \mathrm{t} \mathrm{ha}^{-1}$ de gesso (Novais et al., 1989).

Os incrementos nos teores foliares deP obtidos com as doses degesso, nos três cultivos desoja (Quadro 3), acompanharam os ganhos na disponibilidade do nutriente na camada superficial $(0-5 \mathrm{~cm})$ do solo (Figura 4), avaliados pelo extrator Mehlich-1. O extrator apresentou, portanto, sensibilidade suficiente para detectar as variações desse nutriente no solo ocasionadas pelo uso de gesso. Esses resultados mostram quea utilização de gesso em doses el evadas aumenta a disponibilidade de P na camada superficial do solo, causando reflexos importantes na absorção deP pelas plantas desoja. Não havendo déficit hídrico, o P presente na camada superficial do solo $(0-5 \mathrm{~cm})$ seria suficiente para garantir concentrações adequadas de $P$ no tecido foliar da soja, cultivada em sistema plantio direto.

A redução do $\mathrm{Mg}$ nas folhas de soja, nos três cultivos, decorrente das doses de gesso aplicadas (Quadro 3), mostra claramente que a lixiviação de Mg trocável no solo proporcionada pelo gesso (Figura 2) prejudica a absorção do nutriente pela cultura. Resultados semel hantes têm sido relatados em outros trabal hos real izados com a cultura da soja (Oliveira \& Pavan, 1996; Caires et al., 1998; 1999).

A produção de soja foi pouco influenciada pelos tratamentos de calagem (Quadro 4). A penas no primei ro cultivo, o cal cário incorporado proporcionou maior produção de grãos em comparação à calagem em dose única na superfície, não tendo sido observada influência da calagem na produção de grãos para os demais cultivos de soja. No primeiro cultivo, houve grande precipitação pluvial na época da colheita da soja, o que prejudicou, em parte, a aval iação da produção de grãos, em razão das perdas ocorridas. Mesmo assim, a produção média de grãos do experimento, em três cultivos, foi da ordem de $3.200 \mathrm{~kg} \mathrm{ha}^{-1}$.

Esses resultados diferem dos obtidos por Oliveira \& Pavan (1996) que verificaram, na média de quatro cultivos desoja, em condições semel hantes de sol o e clima, acréscimos na produção de grãos de 32 a 42 \% com a aplicação superficial ou incorporada de cal cário dol omítico. A diferença de resultados pode ser explicada por duas causas principais: oteor mais el evado de Al trocável $\left(8,5 \mathrm{mmol}_{\mathrm{C}} \mathrm{dm}^{-3}\right)$ e o teor bem mais baixo de $\mathrm{Mg}$ trocável $\left(6,6 \mathrm{mmol}_{\mathrm{c}} \mathrm{dm}^{-3}\right)$ no solo estudado por Oliveira \& Pavan (1996), em comparaçãoaos destetrabalho $\left(3 \mathrm{mmol}_{\mathrm{C}} \mathrm{dm}^{-3} \mathrm{deAl}^{3+}\right.$ e $20 \mathrm{mmol}_{\mathrm{C}} \mathrm{dm}^{-3}$ de $\mathrm{Mg}^{2+}$ ). Caires et al. (2001) verificaram aumento na produção de soja com a aplicação de calcário dolomítico na superfície em sistema plantio direto, em decorrência de maior 
Quadro 4. Produção de grãos de soja, consi derando a aplicação da calagem e de doses de gesso no sistema plantio direto

\begin{tabular}{|c|c|c|c|c|}
\hline \multirow{2}{*}{ Tratamento } & \multicolumn{4}{|c|}{ Produção de soja } \\
\hline & 1998/1999 & $1999 / 2000$ & $2000 / 2001$ & Média \\
\hline & & 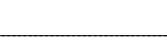 & & - \\
\hline \multicolumn{5}{|l|}{ Calagem } \\
\hline Sem calcário & 1.956 & 3.364 & 3.879 & 3.066 \\
\hline Calcário na superfície(1) & 2.078 & 3.413 & 4.005 & 3.165 \\
\hline Calcário na superfície(2) & 1.862 & 3.662 & 4.217 & 3.247 \\
\hline Calcário incorporado & 2.153 & 3.407 & 4.072 & 3.211 \\
\hline DMS $(P=0,05)$ & 238 & 372 & 493 & 211 \\
\hline C.V. (\%) & 8,4 & 7,6 & 8,6 & 8,1 \\
\hline \multicolumn{5}{|l|}{ Gesso, t ha-1 } \\
\hline 0 & 1.993 & 3.478 & 3.919 & 3.130 \\
\hline 3 & 1.904 & 3.490 & 4.018 & 3.137 \\
\hline 6 & 2.081 & 3.494 & 4.152 & 3.242 \\
\hline & 2.072 & 3.384 & 4.084 & 3.180 \\
\hline Efeito(3) & ns & ns & ns & ns \\
\hline C.V. (\%) & 16,0 & 7,8 & 9,0 & 10,1 \\
\hline
\end{tabular}

(1) 1/3 da dose de calcário aplicada anualmente na superfície por três anos. ${ }^{(2)}$ Dose total de calcário na superfície em uma única aplicação. ${ }^{(3)}$ ns: efeito não-significativo por regressão polinomial.

disponibilidade e absorção de $\mathrm{Mg}$, em solo com $9 \mathrm{mmol}_{\mathrm{c}} \mathrm{dm}^{-3}$ de $\mathrm{Mg}$ trocável, na camada de $0-20 \mathrm{~cm}$. Outro aspecto a ser considerado é que não houve aumento da eficiência da adubação fosfatada com a correção da acidez do solo com a calagem na superfície ou incorporada, em solo com baixo teor de P disponível.

Em sol os ácidos manejados em plantio direto no sul do Brasil, as altas produtividades de soja observadas na ausência de calcário (Caires et al., 1998; Pöttker \& Ben, 1998; Moreira et al., 2001) têm sido atribuídas ao menor efeito tóxico do Al, em conseqüência de menor concentração de espécies tóxicas $\left(\mathrm{Al}^{3+}\right.$ e $\mathrm{AlOH}^{2+}$ ) e maior concentração de $\mathrm{Al}$ complexado com ligantes orgânicos (Miyazawa et al ., 1996; Salet et al., 1999), ou à disponibilidade suficiente de Ca e Mg trocáveis, dada a el evada capacidade de troca de cátions decorrente do alto teor de matéria orgânica (Caires et al., 1998).

Houve ausência de resposta positiva da soja, nos três anos de cultivo, às doses de gesso aplicadas (Quadro 4). Resultados semel hantes têm sido relatados em outros estudos realizados em áreas de cultivos anuais preparadas convencionalmente (Quaggio et al., 1993; Martins et al., 1998) e em sistema plantio direto (Oliveira \& Pavan, 1996; Caires et al., 1998; 1999).

A ausência de resposta da soja à aplicação de gesso pode estar relacionada com o fato de o crescimento do sistema radicular da soja, na ausência de déficit hídrico, não ser influenciado pela redução da saturação por Al no subsolo (Caires et al., 2001). Cabe ressaltar que, no presentetrabal ho, foram encontrados baixos teores de Al trocável nas camadas do subsolo (2 a $5 \mathrm{mmol}_{\mathrm{c}} \mathrm{dm}^{-3}$ ), apesar de ter a análise química, antes da instalação do experimento, revelado a presença de concentração tóxica de $\mathrm{Al}^{3+}\left(8 \mathrm{mmol}_{c} \mathrm{dm}^{-3}\right)$. É possível que essa redução do $\mathrm{Al}^{3+}$ trocável no subsol o tenha ocorrido naturalmente pela presença de resíduos vegetais mantidos na superfície. Recentes trabalhos têm demonstrado redução do Al trocável no solo por materiais vegetais, associada com o aumento do $\mathrm{pH}$ e complexação orgânica (Miyazawa et al., 1993; Franchini et al., 1999).

\section{CONCLUSÕES}

1. A calagem na superfície, com ou sem parcelamento, ou com incorporação, não influenciou a produção média de três cultivos de soja.

2. A aplicação de gesso agrícola foi eficiente na melhoria do ambiente radicular no subsolo, aumentou a concentração deP na camada superficial do sol o e no tecido fol iar da soja, causou redução no teor de $\mathrm{Mg}$ no solo e nas folhas e não ocasionou melhoria na produção de grãos.

\section{LITE RATURA CITADA}

CAIRES, E.F. \& FONSECA, A.F. Absorção de nutrientes pela soja cultivada no sistema de plantio direto em função da calagem na superfície. Bragantia, 59:213-220, 2000. 
CAIRES, E.F.; BANZATTO, D.A. \& FONSECA, A.F. Calagem na superfície em sistema plantio direto. R. Bras. Ci. Solo, 24:161-169, 2000.

CAIRES, E.F.; CHUEIRI, W.A.; MADRUGA, E.F.\& FIGUEIREDO, A. Alterações de características químicas do solo e resposta da soja ao calcário e gesso aplicados na superfície em sistema de cultivo sem preparo do solo. R. Bras. Ci. Solo, 22:27-34, 1998.

CAIRES, E.F.; FONSECA, A.F.; FELDHAUS, I.C. \& BLUM, J . Crescimento radicular e nutrição da soja cultivada no sistema plantio direto em resposta ao calcário e gesso na superfície. R. Bras. Ci. Solo, 25:1029-1040, 2001.

CAIRES, E.F.; FONSECA, A.F.; MENDES, J .; CHUEIRI, W.A. \& MADRUGA, E.F. Produção de milho, trigo e soja em função das alterações das características químicas do solo pela aplicação de cal cário e gesso na superfície, em sistema de plantio direto. R. Bras. Ci. Solo, 23:315-327, 1999.

CAMARGO, A.P.; RAIJ , B. van; CANTARELLA, H.; ROCHA, T.R.; NAGAI, V. \& MASCARENHAS, H.A.A. Efeito da calagem nas produções de cinco cultivos de milho, seguidos de algodão esoja. Pesq. Agropec. Bras., 17:1007-1012, 1982.

CAMARGO, O.A. \& RAIJ , B. van. Movimento do gesso em amostras de Latossolos com diferentes propriedades eletroquímicas. R. Bras. Ci. Solo, 13:275-280, 1989.

CAMERON, R.S.; RITCHIE, G.S.P. \& ROBSON, A.D. Relative toxicities of inorganic aluminum complexes to barley. Soil Sci. Soc. Am. J ., 50:1231-1236, 1986.

CARVALHO, M.C.S. \& RAIJ, B. van. Calcium sulphate, phosphogypsum and cal cium carbonate in the amel ioration of acid subsoils for root growth. Plant Soil, 192:37-48, 1997.

CHAVES, J .C.D.; PAVAN, M.A. \& IGUE, K. Resposta do cafeeiro à calagem. Pesq. Agropec. Bras., 19:573-582, 1984.

COLEMAN, N.T.\& THOMAS, G.W. The basic chemistry of soil acidity. In: PEARSON, R.W. \& ADAMS, F., eds. Soil acidity and liming. Madison, American Society of Agronomy, 1967. p.1-41.

COSTA, A. Doses e modos de aplicação de calcário na implantação de sucessão soja-trigo em sistema plantio direto. Botucatu, Universidade Estadual Paulista, 2000. 146p. (Tese de Doutorado)

EMPRESA BRASILEIRA DE PESQUISA AGROPECUÁRIA EMBRAPA. Centro Nacional dePesquisa de Solos. Manual de métodos de análise de solo. 2.ed. Rio de J aneiro, 1997. $212 p$.

FRANCHINI, J.C.; MALAVOLTA, E.; MIYAZAWA, M. \& PAVAN, M.A. Alterações químicas em solos ácidos após a aplicação de resíduos vegetais. R. Bras. Ci. Solo, 23:533542, 1999.

FREITAS, B.J. A disposição do fosfogesso e seus impactos ambientais. In: SEMINÁRIO SOBRE O USO DO GESSO NA AGRICULTURA, 2., Uberaba, 1992. Anais. Uberaba, IBRAFOS, 1992. p.325-339.

HELYAR, K.R. The management of acid soils. In: WRIGHT, R.J .; BALIGAR, V.C. \& MURRMAN, R.P., eds. Plant-soil interactions at low $\mathrm{pH}$. Dordrecht, Kluwer Academic Publishers, 1991. p.365-382.
MALAVOLTA, E.; VITTI, G.C. \& OLIVEIRA, S.A. Avaliação do estado nutricional das plantas: princípios eaplicações. 2.ed. Piracicaba, POTAFOS, 1997. 319p.

MARSH, B.H. \& GROVE, J.H. Surface and subsurface soil acidity: soybean root responseto sulfate-bearing spent lime. Soil Sci. Soc. Am. J ., 56:1837-1842, 1992.

MARTINS, O.C.; NOVAIS, R.F.; ALVAREZ V., V.H.; BARROS, N.F. \& RIBEIRO, A.C. Respostas à aplicação de diferentes misturas de calcário e gesso em solos. II. Crescimento de raízes, absorção de nutrientes e produtividade da soja. $\mathrm{R}$. Ceres, 45:451-466, 1998.

MASCARENHAS, H.A.A.; BATAGLIA, O.C.; QUAGGIO, J .A. \& GALLO,P.B. Zinco nas folhas de soja em função da calagem. Bragantia, 47:137-142, 1988.

MASCARENHAS, H.A.A.; BRAGA, N.R.; BATAGLIA, O.C.; BULISANI, E.A.; FEITOSA, C.T. \& HIROCE, R. Efeito do corretivo sobre soja cultivada em solo de cerrado contendo Al e Mn. In: SEMINÁRIO NACIONAL DE PESQUISA DE SOJ A, 2., Brasília, 1981. Anais. Londrina, EMBRAPACNPSo, 1982. p.567-573.

MASCARENHAS, H.A.A.; GALLO, J .R.; RAIJ , B. van; IGUE, T. \& BATAGLIA, O.C. Efeitos da calagem nas características químicas do solo e na nutrição de soja em Latossolo Roxo distrófico. Bragantia, 35:273-278, 1976.

MIYAZAWA, M.; PAVAN, M.A. \& CALEGARI, A. Efeito de material vegetal na acidez do solo. R. Bras. Ci. Solo, 17:411416, 1993.

MIYAZAWA, M.; PAVAN, M.A. \& SANTOS, J .C.F. Effects of addition of crop residues on the leaching of $\mathrm{Ca}$ and $\mathrm{Mg}$ in Oxysols. In: INTERNATIONAL SYMPOSIUM ON PLANTSOIL INTERACTIONS AT LOW pH, 4., Belo Horizonte, 1996. Abstracts. Belo Horizonte, Sociedade Brasileira de Ciência do Solo/ EMBRAPA-CPAC, 1996. p.8.

MOREIRA, S.G.; KIEHL, J.C.; PROCHNOW, L.I \& \&AULETTI, $\checkmark$. Calagem em sistema de semeadura direta e efeitos sobre a acidez do solo, disponibilidade de nutrientes e produtividade de milho e soja. R. Bras. Ci. Solo, 25:71-81, 2001.

MUZI LLI, O. Influência do sistema de plantio direto, comparado ao convencional, sobre a fertilidade da camada arável do solo. R. Bras. Ci. Solo, 7:95-102, 1983.

NOVAIS, R.F.; NEVES, J.C.L.; BARROS, N.F. \& SEDIYAMA, T. Deficiência de manganês em plantas de soja cultivadas em solos de cerrado. R. Bras. Ci. Solo, 13:199-204, 1989.

OATES, K.M. \& CALDWELL, A.G. Use of by-product gypsum to alleviate soil acidity. Soil Sci. Soc. Am. J ., 49:915-918, 1985.

OLIVEIRA, E.L. \& PAVAN, M.A. Control of soil acidity in notillage system for soybean production. Soil Till. Res., 38:4757, 1996.

OLIVEIRA, E.L.; PARRA, M.S. \& COSTA, A. Resposta da cultura do milho, em um Latossolo Vermelho-Escuro álico, à calagem. R. Bras. Ci. Solo, 21:65-70, 1997.

OLSEN, S.R. \& WATANABE, F.S. Interaction of added gypsum in alkaline soils with uptake of iron, molybdenum, manganese and zinc by sorghum. Soil Sci. Soc. Am. J., 43:125-130, 1979. 
PAVAN, M.A. Movimentação de calcário no solo através de técnicas de manejo da cobertura vegetal em pomares de macieira. R. Bras. Frutic., 16:86-91, 1994.

PAVAN, M.A.; BINGHAM, F.T. \& PRATT, P.F. Redistribution of exchangeable calcium, magnesium and aluminum following lime and gypsum applications to a Brazilian Oxisol. Soil Sci. Soc. Am. J ., 48:33-38, 1984.

PAVAN, M.A.; BLOCH, M.F.; ZEMPULSKI, H.C.; MIYAZAWA, M. \& ZOCOLER, D.C. Manual de análise química do solo e controle de qualidade. Londrina, Instituto Agronômico do Paraná, 1992. 38p. (Circular, 76)

PÖTTKER, D. \& BEN, J.R. Calagem para uma rotação de culturas no sistema de plantio direto. R. Bras. Ci. Solo, 22:675-684, 1998.

QUAGGIO, J.A.; RAIJ, B. van; GALLO, P.B. \& MASCARENHAS, H.A.A. Respostas da soja à aplicação de calcário e gesso e lixiviação de íons no perfil do solo. Pesq. Agropec. Bras., 28:375-383, 1993.

RAIJ , B. van; CAMARGO, A.P.; MASCARENHAS, H.A.A.; HIROCE, R.; FEITOSA, C.T.; NERY, C. \& LAUN, C.R.P. Efeito de níveis de calagem na produção de soja em solo de cerrado. R. Bras. Ci. Solo, 1:28-31, 1977.

REEVE, N.G. \& SUMNER, M.E. Amelioration of subsoil acidity in Natal Oxisols by leaching of surface applied amendments. Agrochemophysica, 4:1-6, 1972.

RHEINHEIMER, D.S.; SANTOS, E.J.S.; KAMINSKI, J .; BORTOLUZZI, E.C. \& GATIBONI, L.C. Alterações de atributos do solo pela calagem superficial e incorporada a partir de pastagem natural. R. Bras. Ci. Solo, 24:797-805, 2000.
RITCHEY, K.D.; SILVA, S.E. \& COSTA, V.F. Calcium deficiency in clayey B horizons of savannah Oxisols. Soil Sci., 133:378382, 1982.

RITCHEY, K.D.; SOUSA, D.M.G.; LOBATO, E. \& CORREA, O. Calcium leaching to increase rooting depth in a Brazilian Savannah Oxisol. Agron. J ., 72:40-44, 1980.

SALET, R.L.; ANGHINONI, I.\& KOCHHANN, R.A. Atividade dealumínio na solução de um solo no sistema plantio direto. R. Ci. Unicruz, 1:9-13, 1999.

SHAINBERG, I.; SUMNER, M.E.; MILLER, W.P.; FARINA, M.P.W.; PAVAN, M.A. \& FEY, M.V. Use of gypsum on soils: A review. Adv. Soil Sci., 9:1-111, 1989.

SIDIRAS, N. \& PAVAN, M.A. Influência do sistema de manejo do solo no seu nível de fertilidade. R. Bras. Ci. Solo, 9:249254, 1985.

SOUSA, D.M.G.; RITCHEY, K.D. Uso de gesso no solo de cerrado. In: SEMINÁRIO SOBRE O USO DE FOSFOGESSO NA AGRICULTURA, 1., Brasília, 1986. Anais. Brasília, EMBRAPA, DDT, 1986. p.119-144.

SUMNER, M.E.; SHAHANDEH, H.; BOUTON, J \& \& HAMMEL, $J$. Amelioration of an acid soil prolife through deep liming an surface application of gypsum. Soil Sci. Soc. Am. J ., 50:1254-1278, 1986.

TANAKA, R.T.; MASCARENHAS, H.A.A. \& BORKERT, C.M. Nutrição mineral da soja. In: ARANTES, N.E. \& SOUZA, P.I.M., eds. Cultura da soja nos cerrados. Piracicaba, Associação Brasileira para Pesquisa da Potassa e do Fosfato, 1993. p.105-135.

VITTI, G.C. \& SUZUKI,J J.A. A determinação do enxofre-sulfato pelo método turbidimétrico. J aboticabal, Universidade Estadual de São Paulo, 1978. 13p. 